\title{
Common fixed point of the generalized Mizoguchi-Takahashi's type contractions
}

\author{
Mojgan Javahernia ${ }^{1}$, Abdolrahman Razani ${ }^{1 *}$ and Farshid Khojasteh ${ }^{2}$
}

*Correspondence: razani@ipm.ir 'Department of Mathematics, College of Basic Sciences, Karaj Branch, Islamic Azad University, Alborz, Iran

Full list of author information is available at the end of the article

\begin{abstract}
In this work, we introduce a new class of contractive multi-valued mappings, called generalized Mizoguchi-Takahashi's contractions, which is an extension of many known results in the literature. Finally, a partial answer to the conjecture which was introduced by Rouhani and Moradi is given.
\end{abstract}

MSC: $47 \mathrm{H} 10 ; 54 \mathrm{C} 60$

Keywords: multi-valued mapping; Hausdorff metric; Mizoguchi-Takahashi's type; $\mathcal{M T}$-function; GMT-contraction

\section{Introduction}

In 1922, Banach established the most famous fundamental fixed point theorem (the socalled the Banach contraction principle [1]) which has played an important role in various fields of applied mathematical analysis. It is known that the Banach contraction principle has been extended in many various directions by several authors (see [2-7]). An interesting direction of research is the extension of the Banach contraction principle of multi-valued maps, known as Nadler's fixed point theorem [8], Mizoguchi-Takahashi's fixed point theorem [9]; see M Berinde and V Berinde [3], Ćirić [4], Reich [10], Daffer and Kaneko [5], Rhoades [11], Rouhani and Moradi [12], Amini-Harandi [1, 7], Moradi and Khojasteh [13], and $\mathrm{Du}[6]$ and references therein.

Let us recall some basic notations, definitions, and well-known results needed in this paper. Throughout this paper, we denote by $\mathrm{N}$ and $\mathrm{R}$, the sets of positive integers and real numbers, respectively. Let $(X, d)$ be a metric space. For each $x \in X$ and $A \subseteq X$, let $d(x, A)=\inf _{y \in A} d(x, y)$. Denote by $\mathcal{N}(X)$ the class of all nonempty subsets of $X$, by $\mathcal{C}(X)$ the family of all nonempty closed subsets of $X$, and by $\mathcal{C B}(X)$ the family of all nonempty, closed, and bounded subsets of $X$. A function $\mathcal{H}: \mathcal{C B}(X) \times \mathcal{C B}(X) \rightarrow[0, \infty)$ defined by

$$
\mathcal{H}(A, B)=\max \left\{\sup _{x \in B} D(x, A), \sup _{x \in A} D(x, B)\right\}
$$

is said to be the Hausdorff metric on $\mathcal{C B}(X)$ induced by $d$ on $X$ where $D(x, A)=\inf \{d(x, y)$ : $y \in A\}$ for each $A \in \mathcal{C B}(X)$. A point $v$ in $X$ is a fixed point of a map $T$ if $v=T v$ (when $T: X \rightarrow X$ is a single-valued map) or $v \in T v$ (when $T: X \rightarrow \mathcal{N}(X)$ is a multi-valued map). The set of fixed points of $T$ is denoted by $\mathcal{F}(T)$ and the set of common fixed points of two multi-valued mappings $T, S$ is denoted by $\mathcal{F}(T, S)$.

C 2014 Javahernia et al: licensee Springer. This is an Open Access article distributed under the terms of the Creative Commons Attribution License (http://creativecommons.org/licenses/by/2.0), which permits unrestricted use, distribution, and reproduction in any medium, provided the original work is properly cited. 
Definition $1[7, \mathrm{Du}]$ A function $\varphi:[0, \infty) \rightarrow[0,1)$ is said to be an $\mathcal{M} \mathcal{T}$-function (or $\mathcal{R}$ function) if lim $\sup _{s \rightarrow t^{+}} \varphi(s)<1$ for all $t \in[0, \infty)$.

It is evident that if $\varphi:[0, \infty) \rightarrow[0,1)$ is a non-decreasing function or a non-increasing function, then $\varphi$ is an $\mathcal{M T}$-function. So the set of $\mathcal{M T}$-functions is a rich class.

In 1989, Mizoguchi and Takahashi [9] proved a famous generalization of Nadler's fixed point theorem which gives a partial answer to Reich's problem [14].

Theorem 1 [9, Mizoguchi and Takahashi] Let $(X, d)$ be a complete metric space, $\varphi$ : $[0, \infty) \rightarrow[0,1)$ be a $\mathcal{M T}$-function and $T: X \rightarrow \mathcal{C B}(X)$ be a multi-valued map. Assume that

$$
\mathcal{H}(T x, T y) \leq \varphi(d(x, y)) d(x, y)
$$

for all $x, y \in X$. Then $\mathcal{F}(T) \neq \emptyset$.

A mapping $T: X \rightarrow X$ is said to be a weak contraction if there exists $0 \leq \alpha<1$ such that

$$
d(T x, T y) \leq \alpha M(x, y)
$$

for all $x, y \in X$, where

$$
M(x, y):=\max \left\{d(x, y), d(x, T x), d(y, T y), \frac{d(x, T y)+d(y, T x)}{2}\right\} .
$$

Two multi-valued mappings $T, S: X \rightarrow \mathcal{C B}(X)$ are called generalized weak contractions if there exists $0 \leq \alpha<1$ such that

$$
H(T x, S y) \leq \alpha M_{T, S}(x, y)
$$

where

$$
M_{T, S}(x, y):=\max \left\{d(x, y), D(x, T x), D(y, S y), \frac{D(x, S y)+D(y, T x)}{2}\right\} .
$$

Also two mappings $T, S: X \longrightarrow \mathcal{C B}(X)$ are called generalized $\varphi$-weak contractive if there exists a map $\varphi:[0,+\infty) \longrightarrow[0,+\infty)$ with $\varphi(0)=0$ and $\varphi(t)>0$ for all $t>0$ such that

$$
H(T x, S y) \leq M_{T, S}(x, y)-\varphi\left(M_{T, S}(x, y)\right)
$$

for all $x, y \in X$.

The concepts of weak and $\varphi$-weak contractive mappings were defined by Daffer and Kaneko [5] in 1995.

In 2010 Rouhani and Moradi [12] introduced an extension of Daffer and Kaneko's result for two multi-valued weak contraction mappings of a complete metric space $X$ into $\mathcal{C B}(X)$ without assuming $x \mapsto d(x, T x)$ to be l.s.c. 
Theorem 2 Let $(X, d)$ be a complete metric space. Suppose that $T, S: X \rightarrow \mathcal{C B}(X)$ are contraction mappings in the sense that, for some $0 \leq \alpha<1$,

$$
H(T x, S y) \leq \alpha M_{T, S}(x, y)
$$

for all $x, y \in X$ (i.e., weak contractions). Then there exists a point $x_{0} \in X$ such that $x_{0} \in T x_{0}$ and $x_{0} \in S x_{0}$.

The paper is organized as follows. In Section 2, we first introduce the Generalized Mizoguchi-Takahashi's Contraction (GMT for short) as an extension of Mizoguchi and Takahashi's type and of work by Daffer and Kaneko. Section 3 is dedicated to the study of some new fixed point theorems, which generalize and improve Mizoguchi-Takahashi's fixed point theorem, Nadler's fixed point theorem, and some well-known results. Furthermore, we give a partial answer to the conjecture introduced by Rouhani and Moradi (see [12, Theorem 4.1 and Section 5]). Consequently, some of our results in this paper are original in the literature, and we obtain many results in the literature as special cases.

\section{Main result}

In this section, we first explain the concept of GMT contraction (see also $[9,15])$.

Definition 2 A function $\vartheta: R \times R \rightarrow R$ is called a GMT function if the following conditions hold:

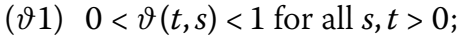

$(\vartheta 2)$ for any bounded sequence $\left\{t_{n}\right\} \subset(0,+\infty)$ and any non-increasing sequence $\left\{s_{n}\right\} \subset$ $(0,+\infty)$, we have

$$
\limsup _{n \rightarrow \infty} \vartheta\left(t_{n}, s_{n}\right)<1
$$

We denote the set of all GMT functions by $\widehat{\mathrm{GMT}(\mathrm{R})}$.

Here, we give simple examples of manageable functions.

Example $1[15$, Example B] Let $\varphi:[0, \infty) \rightarrow[0,1)$ be an $\mathcal{M T}$-function, then $\vartheta(t, s)=\varphi(s)$ is a GMT-function.

Example 2 Let $g(x)=\frac{\ln (x+10)}{x+9}$ for all $x>-9$. Define

$$
\vartheta(t, s)= \begin{cases}\frac{t}{s^{2}+1}, & 1<t<s, \\ g(s), & \text { otherwise. }\end{cases}
$$

It is clear that $0<\vartheta(t, s)<1$. Also for any bounded sequence $\left\{t_{n}\right\} \subset(0,+\infty)$ and any nonincreasing sequence $\left\{s_{n}\right\} \subset(0,+\infty)$, if $1<t_{n}<s_{n}$, then $\lim _{n \rightarrow \infty} s_{n}=\inf _{n \in \mathrm{N}} s_{n}=a$ for some $a \in[0,+\infty)$. We have

$$
\limsup _{n \rightarrow \infty} \vartheta\left(t_{n}, s_{n}\right)=\limsup _{n \rightarrow \infty} \frac{t_{n}}{s_{n}^{2}+1} \leq \lim _{n \rightarrow \infty} \frac{s_{n}}{s_{n}^{2}+1}=\frac{a}{a^{2}+1}<1 .
$$


Otherwise, $\vartheta(t, s)=g(s)$ and since $g$ is continuous, we get

$$
\limsup _{n \rightarrow \infty} \vartheta\left(t_{n}, s_{n}\right)=\lim _{n \rightarrow \infty} g\left(s_{n}\right)=g(a)<1
$$

which means that $(\vartheta 2)$ holds. Hence $\vartheta \in \widehat{\mathrm{GMT}}(\mathrm{R})$.

Definition 3 Let $(X, d)$ be a metric space. The mapping $T: X \rightarrow \mathcal{C B}(X)$ is called a WGMTcontraction if there exists $\vartheta \in \widehat{\mathrm{GMT}}(\mathrm{R})$ such that

$$
\mathcal{H}(T x, T y) \leq \vartheta\left(\mathcal{H}(T x, T y), M_{T}(x, y)\right) M_{T}(x, y)
$$

for each $x, y \in X$.

Theorem 3 Let $(X, d)$ be a complete metric space and let $T, S: X \rightarrow \mathcal{C B}(X)$ and suppose there exists $\vartheta \in \widehat{\mathrm{GMT}(\mathrm{R})}$ such that

$$
\mathcal{H}(T x, S y) \leq \vartheta\left(\mathcal{H}(T x, S y), M_{T, S}(x, y)\right) M_{T, S}(x, y)
$$

for each $x, y \in X$. Then $T, S$ have a common fixed point.

Proof Let $x_{0} \in X$ be arbitrary and $x_{1} \in S x_{0}$. Since $T x_{1} \neq \emptyset$ choose $x_{2} \in T x_{1}$. If $x_{1}=x_{2}$ we have nothing to prove, because

$$
M_{T, S}\left(x_{1}, x_{2}\right)=\max \left\{d\left(x_{1}, x_{2}\right), D\left(x_{1}, T x_{1}\right), D\left(x_{2}, S x_{2}\right), \frac{D\left(x_{1}, S x_{2}\right)+D\left(x_{2}, T x_{1}\right)}{2}\right\} .
$$

Thus $M_{T, S}\left(x_{1}, x_{2}\right)=D\left(x_{2}, S x_{2}\right)$. If $D\left(x_{2}, S x_{2}\right)=0$, then $x_{2} \in S x_{2}$ and $x_{2} \in T x_{1}=T x_{2}$ and so $x_{2}$ is the common fixed point of $T, S$. Hence without loss of generality, we can assume that $M_{T, S}\left(x_{1}, x_{2}\right)>0$. Also if $\mathcal{H}\left(T x_{1}, S x_{2}\right)=0$, then $T x_{1}=S x_{2}$ and since $x_{1}=x_{2}$ we have $x_{2} \in T x_{1}=T x_{2}$ and $x_{2} \in T x_{1}=S x_{2}$ and again $x_{2}$ is the common fixed point of $T, S$. Thus we can assume that $\mathcal{H}\left(T x_{1}, S x_{2}\right)>0$. Therefore, by any choice of $x_{1}, x_{2}$ we can assume that

- $M_{T, S}\left(x_{1}, x_{2}\right)>0$,

- $\mathcal{H}\left(T x_{1}, S x_{2}\right)>0$.

Taking

$$
\epsilon_{1}=\left(\frac{1}{\sqrt{\vartheta\left(\mathcal{H}\left(T x_{1}, S x_{2}\right), M_{T, S}\left(x_{1}, x_{2}\right)\right)}}-1\right) \mathcal{H}\left(T x_{1}, S x_{2}\right)
$$

(note that $\epsilon_{1}>0$ ), there exists $x_{3} \in S x_{2}$ such that $x_{3} \neq x_{2}$ such that

$$
\begin{aligned}
d\left(x_{3}, x_{2}\right) & <\mathcal{H}\left(T x_{1}, S x_{2}\right)+\epsilon_{1} \\
& =\frac{\mathcal{H}\left(T x_{1}, S x_{2}\right)}{\sqrt{\vartheta\left(\mathcal{H}\left(T x_{1}, S x_{2}\right), M_{T, S}\left(x_{1}, x_{2}\right)\right)}} .
\end{aligned}
$$

By the above argument, we can assume that

- $M_{T, S}\left(x_{2}, x_{3}\right)>0$,

- $\mathcal{H}\left(T x_{2}, S x_{3}\right)>0$. 
Choose $x_{4} \in T x_{3}$. Taking

$$
\epsilon_{2}=\left(\frac{1}{\sqrt{\vartheta\left(\mathcal{H}\left(T x_{3}, S x_{4}\right), M_{T, S}\left(x_{3}, x_{4}\right)\right)}}-1\right) \mathcal{H}\left(T x_{3}, S x_{4}\right)
$$

(note that $\epsilon_{2}>0$ ), there exists $x_{5} \in S x_{4}$ such that $x_{5} \neq x_{4}$ and

$$
\begin{aligned}
d\left(x_{5}, x_{4}\right) & <\mathcal{H}\left(T x_{3}, S x_{4}\right)+\epsilon_{2} \\
& =\frac{\mathcal{H}\left(T x_{3}, S x_{4}\right)}{\sqrt{\vartheta\left(\mathcal{H}\left(T x_{3}, S x_{4}\right), M_{T, S}\left(x_{3}, x_{4}\right)\right)}} .
\end{aligned}
$$

By induction, if $x_{2 k-1}, x_{2 k}, x_{2 k+1} \in X$ is known to satisfy $x_{2 k} \in T x_{2 k-1}, x_{2 k+1} \in S x_{2 k}, \mathcal{H}\left(T x_{2 k-2}\right.$, $\left.S x_{2 k-1}\right)>0, M_{T, S}\left(x_{2 k-2}, x_{2 k-1}\right)>0$, and

$$
\begin{aligned}
d\left(x_{2 k}, x_{2 k+1}\right) & <\mathcal{H}\left(T x_{2 k-1}, S x_{2 k}\right)+\epsilon_{k-1} \\
& =\frac{\mathcal{H}\left(T x_{2 k-1}, S x_{2 k}\right)}{\sqrt{\vartheta\left(\mathcal{H}\left(T x_{2 k-1}, S x_{2 k}\right), M_{T, S}\left(x_{2 k-1}, x_{2 k}\right)\right)}},
\end{aligned}
$$

then, by taking

$$
\epsilon_{k}=\left(\frac{1}{\left.\sqrt{\vartheta\left(\mathcal{H}\left(T x_{2 k}, T x_{2 k+1}\right), M_{T, S}\left(x_{2 k}, x_{2 k+1}\right)\right.}\right)}-1\right) \mathcal{H}\left(T x_{2 k}, S x_{2 k+1}\right),
$$

one can obtain $x_{2 k+3} \in S x_{2 k+2}$ with $x_{2 k+3} \neq x_{2 k+2}$ such that

$$
\begin{aligned}
d\left(x_{2 k+2}, x_{2 k+3}\right) & <\mathcal{H}\left(T x_{2 k+1}, S x_{2 k+2}\right)+\epsilon_{k} \\
& =\frac{\mathcal{H}\left(T x_{2 k+1}, S x_{2 k+2}\right)}{\sqrt{\vartheta\left(\mathcal{H}\left(T x_{2 k+1}, S x_{2 k+2}\right), M_{T, S}\left(x_{2 k+1}, x_{2 k+2}\right)\right)}} .
\end{aligned}
$$

Hence by induction, we can establish a sequence $\left\{x_{2 n+1}\right\}$ in $X$ satisfying, for each $n \in \mathrm{N}$,

- $x_{2 n+1} \in S x_{2 n}$,

- $\mathcal{H}\left(T x_{2 n-2}, S x_{2 n-1}\right)>0$,

- $M_{T, S}\left(x_{2 n-2}, x_{2 n-1}\right)>0$,

and

$$
\begin{aligned}
d\left(x_{2 n}, x_{2 n+1}\right) & <\mathcal{H}\left(T x_{2 n-1}, S x_{2 n}\right)+\epsilon_{n-1} \\
& =\frac{\mathcal{H}\left(T x_{2 n-1}, S x_{2 n}\right)}{\sqrt{\vartheta\left(\mathcal{H}\left(T x_{2 n-1}, S x_{2 n}\right), M_{T, S}\left(x_{2 n-1}, x_{2 n}\right)\right)}} .
\end{aligned}
$$

By (7), we have

$$
\mathcal{H}\left(T x_{2 n-1}, S_{2 n}\right) \leq \vartheta\left(\mathcal{H}\left(T x_{2 n-1}, S_{2 n}\right), M_{T, S}\left(x_{2 n-1}, x_{2 n}\right)\right) M_{T, S}\left(x_{2 n-1}, x_{2 n}\right) .
$$

By combining (11) and (12), we get

$$
d\left(x_{2 n}, x_{2 n+1}\right)<\sqrt{\vartheta\left(\mathcal{H}\left(T x_{2 n-1}, S x_{2 n}\right), M_{T, S}\left(x_{2 n-1}, x_{2 n}\right)\right)} M_{T, S}\left(x_{2 n-1}, x_{2 n}\right) .
$$


By repeating the above argument (replacing $S$ by $T$ ) one can easily verified that

$$
d\left(x_{2 n+2}, x_{2 n+1}\right)<\sqrt{\vartheta\left(\mathcal{H}\left(T x_{2 n}, S x_{2 n+1}\right), M_{T, S}\left(x_{2 n}, x_{2 n+1}\right)\right)} M_{T, S}\left(x_{2 n}, x_{2 n+1}\right) .
$$

Note that

$$
\begin{aligned}
d\left(x_{2 n-1}, x_{2 n}\right) \leq & M_{T, S}\left(x_{2 n-1}, x_{2 n}\right) \\
= & \max \left\{d\left(x_{2 n-1}, x_{2 n}\right), D\left(x_{2 n-1}, T x_{2 n-1}\right), D\left(x_{2 n}, S x_{2 n}\right),\right. \\
& \left.\frac{D\left(x_{2 n}, T x_{2 n-1}\right)+D\left(x_{2 n-1}, S x_{2 n}\right)}{2}\right\} \\
\leq & \max \left\{d\left(x_{2 n-1}, x_{2 n}\right), d\left(x_{2 n+1}, x_{2 n}\right), \frac{d\left(x_{2 n-1}, x_{2 n+1}\right)}{2}\right\} \\
\leq & \max \left\{d\left(x_{2 n-1}, x_{2 n}\right), d\left(x_{2 n+1}, x_{2 n}\right), \frac{d\left(x_{2 n}, x_{2 n-1}\right)+d\left(x_{2 n}, x_{2 n+1}\right)}{2}\right\} \\
= & \max \left\{d\left(x_{2 n}, x_{2 n-1}\right), d\left(x_{2 n+1}, x_{2 n}\right)\right\} \\
= & d\left(x_{2 n-1}, x_{2 n}\right) \quad(\mathrm{by}(13)) .
\end{aligned}
$$

Also

$$
\begin{aligned}
d\left(x_{2 n+1}, x_{2 n}\right) \leq & M_{T, S}\left(x_{2 n+1}, x_{2 n}\right) \\
= & \max \left\{d\left(x_{2 n+1}, x_{2 n}\right), D\left(x_{2 n+1}, T x_{2 n+1}\right), D\left(x_{2 n}, S x_{2 n}\right),\right. \\
& \left.\frac{D\left(x_{2 n}, T x_{2 n+1}\right)+D\left(x_{2 n+1}, S x_{2 n}\right)}{2}\right\} \\
\leq & \max \left\{d\left(x_{2 n+1}, x_{2 n}\right), d\left(x_{2 n+1}, x_{2 n+2}\right), \frac{d\left(x_{2 n}, x_{2 n+2}\right)}{2}\right\} \\
\leq & \max \left\{d\left(x_{2 n-1}, x_{2 n}\right), d\left(x_{2 n+1}, x_{2 n}\right), \frac{d\left(x_{2 n}, x_{2 n+1}\right)+d\left(x_{2 n+1}, x_{2 n+2}\right)}{2}\right\} \\
= & \max \left\{d\left(x_{2 n}, x_{2 n+1}\right), d\left(x_{2 n+1}, x_{2 n+2}\right)\right\} \\
= & d\left(x_{2 n+1}, x_{2 n}\right) \quad(\mathrm{by}(14)) .
\end{aligned}
$$

It means that $d\left(x_{2 n-1}, x_{2 n}\right)=M_{T, S}\left(x_{2 n-1}, x_{2 n}\right)$ and $M_{T, S}\left(x_{2 n+1}, x_{2 n}\right)=d\left(x_{2 n+1}, x_{2 n}\right)$. Hence for each $n \in \mathrm{N}$ we have

$$
d\left(x_{n}, x_{n+1}\right)<\sqrt{\vartheta\left(\mathcal{H}\left(T x_{n}, S x_{n-1}\right), d\left(x_{n}, x_{n-1}\right)\right)} d\left(x_{n}, x_{n-1}\right),
$$

which means that the sequence $\left\{d\left(x_{n-1}, x_{n}\right)\right\}_{n \in \mathrm{N}}$ is strictly decreasing in $(0,+\infty)$. So

$$
\gamma:=\lim _{n \rightarrow \infty} d\left(x_{n}, x_{n+1}\right)=\inf _{n \in \mathrm{N}} d\left(x_{n}, x_{n+1}\right) \geq 0 \quad \text { exists. }
$$

By (12) and (15), we have

$$
\mathcal{H}\left(T x_{n}, S x_{n-1}\right) \leq d\left(x_{n-1}, x_{n}\right) \quad \text { for all } n \in \mathrm{N} \text {, }
$$




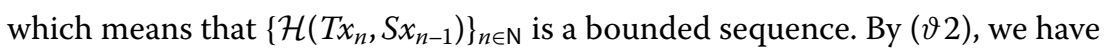

$$
\limsup _{n \rightarrow \infty} \vartheta\left(\mathcal{H}\left(T x_{n}, S x_{n-1}\right), d\left(x_{n-1}, x_{n}\right)\right)<1
$$

Now, we claim $\gamma=0$. Suppose $\gamma>0$. Then, by (18) and taking the limsup in both sides of (13), we get

$$
\gamma \leq \sqrt{\limsup _{n \rightarrow \infty} \vartheta\left(\mathcal{H}\left(T x_{n-1}, S x_{n}\right), d\left(x_{n-1}, x_{n}\right)\right)} \gamma<\gamma,
$$

a contradiction. Hence we prove

$$
\lim _{n \rightarrow \infty} d\left(x_{n}, x_{n+1}\right)=\inf _{n \in \mathrm{N}} d\left(x_{n}, x_{n+1}\right)=0 .
$$

To complete the proof it suffices to show that $\left\{x_{n}\right\}_{n \in \mathrm{N}}$ is a Cauchy sequence in $X$.

For each $n \in \mathrm{N}$, let

$$
\rho_{n}:=\sqrt{\vartheta\left(\mathcal{H}\left(T x_{n-1}, S x_{n}\right), d\left(x_{n-1}, x_{n}\right)\right)}
$$

Then $\rho_{n} \in(0,1)$ for all $n \in \mathrm{N}$. By $(13)$, we obtain

$$
d\left(x_{n}, x_{n+1}\right)<\rho_{n} d\left(x_{n-1}, x_{n}\right) \quad \text { for all } n \in \mathrm{N} \text {. }
$$

From (18), we have $\lim \sup _{n \rightarrow \infty} \rho_{n}<1$, so there exist $c \in[0,1)$ and $n_{0} \in \mathrm{N}$, such that

$$
\rho_{n} \leq c \quad \text { for all } n \in \mathrm{N} \text { with } n \geq n_{0} \text {. }
$$

For any $n \geq n_{0}$, since $\rho_{n} \in(0,1)$ for all $n \in \mathrm{N}$ and $c \in[0,1)$, taking into account (20) and (21), we conclude that

$$
\begin{aligned}
d\left(x_{n}, x_{n+1}\right) & <\rho_{n} d\left(x_{n-1}, x_{n}\right) \\
& <\cdots \\
& <\rho_{n} \rho_{n-1} \rho_{n-2} \cdots \rho_{n 0} d\left(x_{0}, x_{1}\right) \\
& \leq c^{n-n_{0}+1} d\left(x_{0}, x_{1}\right) .
\end{aligned}
$$

Put $\alpha_{n}=\frac{c^{n-n_{0}+1}}{1-c} d\left(x_{0}, x_{1}\right), n \in \mathrm{N}$. For $m, n \in \mathrm{N}$ with $m>n \geq n_{0}$, we have from the last inequality

$$
d\left(x_{n}, x_{m}\right) \leq \sum_{j=n}^{m-1} d\left(x_{j}, x_{j+1}\right)<\alpha_{n}
$$

Since $c \in[0,1), \lim _{n \rightarrow \infty} \alpha_{n}=0$ and hence

$$
\lim _{n \rightarrow \infty} \sup \left\{d\left(x_{n}, x_{m}\right): m>n\right\}=0 .
$$


So $\left\{x_{n}\right\}$ is a Cauchy sequence in $X$ and converges to $x^{*} \in X$. If

$$
S=\left\{n \in \mathrm{N}: x_{n}=x^{*}\right\}
$$

and $\sharp(S)=\infty$ where $\sharp(S)$ is the cardinal number of $S$, then $x_{n+1} \in T x_{n}=T x^{*}$ and we have $x^{*} \in T x^{*}$. If $\sharp(S)<\infty$ one deduces that there exists $\ell \in \mathrm{N}$ such that $x_{n} \neq x$ for all $n \in \mathrm{N}$ with $n \geq \ell$. It means that $\mathcal{H}\left(T x_{n}, S x^{*}\right)>0$ and $d\left(x_{n}, x^{*}\right)>0$ for each $n \geq \ell$. Hence $\mathcal{H}\left(T x_{n}, S x^{*}\right)>0$ and $M_{T, S}\left(x_{n}, x^{*}\right)>0$ for each $n \geq \ell$ and so

$$
\begin{aligned}
D\left(x_{n+1}, T x^{*}\right) & \leq \mathcal{H}\left(T x_{n}, S x^{*}\right) \\
& \leq \vartheta\left(\mathcal{H}\left(T x_{n}, S x^{*}\right), M_{T, S}\left(x_{n}, x^{*}\right)\right) M_{T, S}\left(x_{n}, x^{*}\right) \\
& <M_{T, S}\left(x_{n}, x^{*}\right) .
\end{aligned}
$$

Suppose that $D\left(T x^{*}, x^{*}\right)>0$, then

$$
\begin{aligned}
M_{T, S}\left(x_{n}, x^{*}\right) & =\max \left\{d\left(x_{n}, x^{*}\right), D\left(T x^{*}, x^{*}\right), D\left(x_{n}, S x_{n}\right), \frac{D\left(x_{n}, T x^{*}\right)+D\left(S x_{n}, x^{*}\right)}{2}\right\} \\
& \leq \max \left\{d\left(x_{n}, x^{*}\right), D\left(T x^{*}, x^{*}\right), d\left(x_{n}, x_{n+1}\right), \frac{D\left(x_{n}, T x^{*}\right)+d\left(x_{n+1}, x^{*}\right)}{2}\right\} .
\end{aligned}
$$

By (23) one can choose $v \in \mathrm{N}$ such that $M_{T, S}\left(x_{n}, x^{*}\right)=D\left(T x^{*}, x^{*}\right)$ for each $n \geq v$. Now by taking $\kappa=\max \{v, \ell\}$, for each $n \geq \kappa$ we have

$$
\begin{aligned}
D\left(x_{n+1}, T x^{*}\right) & \leq \mathcal{H}\left(S x_{n}, T x^{*}\right) \\
& \leq \vartheta\left(\mathcal{H}\left(S x_{n}, T x^{*}\right), D\left(T x^{*}, x^{*}\right)\right) D\left(T x^{*}, x^{*}\right) \\
& <D\left(T x^{*}, x^{*}\right) .
\end{aligned}
$$

For each $n \in \mathrm{N}$, let

$$
\lambda_{n}:=\sqrt{\vartheta\left(\mathcal{H}\left(S x_{n}, T x^{*}\right), D\left(T x^{*}, x^{*}\right)\right)} .
$$

Then $\rho_{n} \in(0,1)$ for all $n \in \mathrm{N}$. By $(24)$, we obtain

$$
D\left(x_{n+1}, T x^{*}\right) \leq \mathcal{H}\left(S x_{n}, T x^{*}\right)<\lambda_{n} D\left(T x^{*}, x^{*}\right)<D\left(T x^{*}, x^{*}\right) \text { for all } n \geq \kappa .
$$

Since $\mathcal{H}\left(S x_{n}, T x^{*}\right) \leq D\left(T x^{*}, x^{*}\right)$ we have $\left\{\mathcal{H}\left(S x_{n}, T x^{*}\right)\right\}$ is bounded and $\left\{D\left(T x^{*}, x^{*}\right)\right\}$ is a fixed sequence. From $\left(\eta_{2}\right)$, we have $\lim \sup _{n \rightarrow \infty} \lambda_{n}<1$, so there exist $r \in[0,1)$ and $n_{0} \in \mathrm{N}$, such that

$$
\lambda_{n} \leq r \quad \text { for all } n \in \mathrm{N} \text { with } n \geq n_{0} .
$$

Taking the limit in both sides of (25) we have

$$
D\left(x^{*}, T x^{*}\right) \leq r D\left(T x^{*}, x^{*}\right) .
$$


Thus $r \geq 1$ and this is a contradiction. So we have $D\left(x^{*}, T x^{*}\right)=0$ and then $x^{*} \in T x^{*}$. The same argument can be applied for $S$ and one can easily verify that $x^{*} \in S x^{*}$ and so $T, S$ have a common fixed point $x^{*} \in X$.

In the following, an example is given covering our result.

Example 3 Suppose that $X=[0,1] \cup\{4\}$ and let $T, S: X \rightarrow \mathcal{C B}(X)$ be defined as follows:

$$
T x=\left[0, \frac{x}{4}\right] \text { and } S y=\left\{\frac{y}{4}\right\} .
$$

Suppose that

$$
\varphi(t)= \begin{cases}\frac{t}{2}, & t \in[0,1] \\ \frac{3 t}{4}, & t>1\end{cases}
$$

and $\vartheta(t, s)=1-\frac{\varphi(s)}{s}$ for all $t, s>0$. For any bounded sequence $\left\{t_{n}\right\} \subset(0,+\infty)$ and any nonincreasing sequence $\left\{s_{n}\right\} \subset(0,+\infty)$, we have

$$
\limsup _{n \rightarrow \infty} \vartheta\left(t_{n}, s_{n}\right)=\limsup _{n \rightarrow \infty}\left(1-\frac{\varphi\left(s_{n}\right)}{s_{n}}\right)<1 .
$$

First suppose $0 \leq x \leq 1$ and $0 \leq y \leq 1$, then

$$
\begin{aligned}
\mathcal{H}(T x, S y) & =\max \left\{\left|\frac{y}{4}-\frac{x}{4}\right|, \frac{y}{4}\right\} \\
& \leq \frac{1}{2} \max \left\{|y-x|,\left|y-\frac{y}{4}\right|\right\} \\
& \leq \frac{1}{2} M_{T, S}(x, y) \\
& =\vartheta\left(\mathcal{H}(T x, S y), M_{T, S}(x, y)\right) M_{T, S}(x, y) .
\end{aligned}
$$

In the other case, suppose $x=4$ and $0 \leq y \leq 1$, then

$$
\begin{aligned}
\mathcal{H}(T x, S y) & =\max \left\{\left|\frac{y}{4}-1\right|, \frac{y}{4}\right\} \\
& \leq \frac{1}{4} \max \{4-y, y\} \\
& \leq \frac{1}{4} M_{T, S}(x, y) \\
& =\vartheta\left(\mathcal{H}(T x, S y), M_{T, S}(x, y)\right) M_{T, S}(x, y) .
\end{aligned}
$$

Other cases are easily verified as the above arguments. Henceforth, $T$ is a WGMTcontraction and enjoys all conditions of Theorem 3. Also, $T, S$ have a common fixed point $\{0\}$. 


\section{Consequences}

Here we deduce some of the known and unknown results by Theorem 3 .

Corollary 1 Let $(X, d)$ be a complete metric space and $T, S: X \rightarrow \mathcal{C B}(X)$ be two multivalued mappings such that

$$
\mathcal{H}(T x, S y) \leq \alpha M_{T, S}(x, y) \quad \text { for all } x, y \in X
$$

where $\alpha \in[0,1)$. Then $T, S$ have at least a common fixed point in $X$.

Proof It suffices to take $\vartheta(t, s)=\alpha$ and apply Theorem 3 .

Corollary 2 Let $(X, d)$ be a complete metric space and $T, S: X \rightarrow \mathcal{C B}(X)$ be two multivalued mappings such that

$$
\mathcal{H}(T x, S y) \leq \varphi\left(M_{T, S}(x, y)\right) M_{T, S}(x, y) \quad \text { for all } x, y \in X,
$$

where $\varphi:[0,+\infty) \rightarrow[0,1)$ be an $\mathcal{M T}$-function, then $T$ has a fixed point in $X$.

Proof It suffices to take $\vartheta(t, s)=\varphi(s)$ and apply Theorem 3 .

Corollary 3 [13, Generalized weak contraction] Let $(X, d)$ be a complete metric space and $T, S: X \rightarrow \mathcal{C B}(X)$ be two multi-valued mappings such that

$$
\mathcal{H}(T x, S y) \leq \varphi\left(M_{T, S}(x, y)\right) \quad \text { for all } x, y \in X,
$$

where $\varphi:[0,+\infty) \rightarrow[0,1)$ be a function such that $\varphi(s)<s$ and $\lim _{\sup } \operatorname{sit}_{s} \frac{\varphi(s)}{s}<1$. Then $T$ has a fixed point in $X$.

Proof It suffices to take $\vartheta(t, s)=\frac{\varphi(s)}{s}$ and apply Theorem 3 .

\section{A partial answer to a known conjecture}

In 2010, Rouhani and Moradi [12] proved the following theorem.

Corollary 4 Let $(X, d)$ be a complete metric space and let $T: X \rightarrow X$ and $S: X \rightarrow \mathcal{C B}(X)$ be two mappings such that, for all $x, y \in X$,

$$
\mathcal{H}(\{T x\}, S y) \leq M_{T, S}(x, y)-\varphi\left(M_{T, S}(x, y)\right) \quad \text { for all } x, y \in X
$$

(i.e. generalized $\varphi$-weak contractions) where $\varphi:[0,+\infty) \rightarrow[0,+\infty)$ is l.s.c. with $\varphi(0)=0$, $\varphi(t)<t$ and $\varphi(t)>0$ for all $t>0$. Then there exists a unique point $x \in X$ such that $T x=x \in$ $S x$.

Motivated by the above the authors extended Rhoades's theorem by assuming $\varphi$ to be only l.s.c., as well as Zhang and Song's [16] theorem to the case where one of the mappings is multi-valued. They also asserted the following: 'Future directions to be pursued in the context of this research include the investigation of the case where both mappings 
in Zhang and Song's theorem are multi-valued.' By research in the literature such as $[1,7]$ and specially [16] (see [16, Problem 3.2]) one deduces the following problem, a conjecture in the literature.

Problem (A) Let $(X, d)$ be a complete metric space and let $T, S: X \rightarrow \mathcal{C B}(X)$ be two mappings such that, for all $x, y \in X$,

$$
\mathcal{H}(T x, S y) \leq M_{T, S}(x, y)-\varphi\left(M_{T, S}(x, y)\right), \quad \text { for all } x, y \in X
$$

(i.e. generalized $\varphi$-weak contractions) where $\varphi:[0,+\infty) \rightarrow[0,+\infty)$ is l.s.c. with $\varphi(0)=0$, $\varphi(t)<t$ and $\varphi(t)>0$, for all $t>0$. Then do $T$ and $S$ have a common fixed point?

Definition 4 We say that $\varphi:[0,+\infty) \rightarrow[0,+\infty)$ is a weak l.s.c. function if for each bounded sequence $\left\{t_{n}\right\} \subset(0, \infty)$,

$$
\liminf _{n \rightarrow \infty} \varphi\left(t_{n}\right)>0
$$

The collection of all weak l.s.c. functions is denoted by $\mathcal{W}_{\text {lsc }}(\mathrm{R})$.

In the following theorem a partial solution to Problem (A) is given as an application of Theorem 3.

Corollary 5 Let $(X, d)$ be a complete metric space and let $T, S: X \rightarrow \mathcal{C B}(X)$ be two mappings such that, for all $x, y \in X$,

$$
\mathcal{H}(T x, S y) \leq M_{T, S}(x, y)-\varphi\left(M_{T, S}(x, y)\right) \quad \text { for all } x, y \in X
$$

(i.e. generalized $\varphi$-weak contractions) where $\varphi:[0,+\infty) \rightarrow[0,+\infty)$, with $\varphi(0)=0, \varphi(t)<t$ and $\varphi \in \mathcal{W}_{\mathrm{lsc}}(\mathrm{R})$. Then $\mathcal{F} i x(T, S) \neq \emptyset$.

Proof Define $\vartheta(t, s)=\left(1-\frac{\varphi(t)}{t}\right)$, for all $t, s>0$. Since for each bounded sequence $\left\{t_{n}\right\} \subset$ $(0, \infty), \liminf _{n \rightarrow \infty} \varphi\left(t_{n}\right)>0$, thus $\liminf _{n \rightarrow \infty} \frac{\varphi\left(t_{n}\right)}{t_{n}}>0$. Thus,

$$
\limsup _{n \rightarrow \infty}\left(1-\frac{\varphi\left(t_{n}\right)}{t_{n}}\right)=1-\liminf _{n \rightarrow \infty} \frac{\varphi\left(t_{n}\right)}{t_{n}}<1 .
$$

It means that $\vartheta \in \widehat{\mathrm{GMT}(\mathrm{R})}$. Also

$$
\mathcal{H}(T x, S y) \leq \vartheta\left(M_{T, S}(x, y),(d(x, y))\right) M_{T, S}(x, y) .
$$

Applying Theorem 3 yields $\mathcal{F} i x(T, S) \neq \emptyset$. 


\section{Author details}

${ }^{1}$ Department of Mathematics, College of Basic Sciences, Karaj Branch, Islamic Azad University, Alborz, Iran. ${ }^{2}$ Department of Mathematics, Arak Branch, Islamic Azad University, Arak, Iran.

Received: 1 May 2014 Accepted: 28 August 2014 Published: 24 September 2014

\section{References}

1. Amini-Harandi, A: Endpoints of set-valued contractions in metric spaces. Nonlinear Anal. TMA 72, 132-134 (2010)

2. Banach, S: Sur les opérations dans les ensembles abstraits et leurs applications aux équations intégrales. Fundam. Math. 3, 133-181 (1922)

3. Berinde, M, Berinde, V: On a general class of multi-valued weakly Picard mappings. J. Math. Anal. Appl. 326, 772-782 (2007)

4. Cirić, LB: Generalized contraction and fixed point theorems. Publ. Inst. Math. (Belgr.) 12, 19-26 (1971)

5. Daffer, PZ, Kaneko, H: Fixed points of generalized contractive multi-valued mappings. J. Math. Anal. Appl. 192, 655-666 (1995)

6. Du, W-S: On coincidence point and fixed point theorems for nonlinear multi-valued maps. Topol. Appl. 159, 49-56 (2012)

7. Hussain, N, Amini-Harandi, A, Cho, YJ: Approximate endpoints for set valued contractions in metric spaces. Fixed Point Theory Appl. 2010, Article ID 614867 (2010). doi:10.1155/2010/614867

8. Nadler, SB: Multi valued contraction mappings. Pac. J. Math. 30, 475-488 (1969)

9. Mizoguchi, N, Takahashi, W: Fixed-point theorems for multi valued mappings on complete metric spaces. J. Math Anal. Appl. 141, 177-188 (1989)

10. Reich, S: Fixed points of contractive functions. Boll. Unione Mat. Ital. 5, 26-42 (1972)

11. Rhoades, BE: Some theorems on weakly contractive maps. Nonlinear Anal. TMA 47, 2683-2693 (2001)

12. Rouhani, BD, Moradi, S: Common fixed-point of multi valued generalized $\phi$-weak contractive mappings. Fixed Point Theory Appl. (2010). doi:10.1155/2010/708984

13. Moradi, S, Khojasteh, F: Endpoints of multi valued generalized weak contraction mappings. Nonlinear Anal. TMA 74, 2170-2174 (2011)

14. Reich, S: Some problems and results in fixed point theory. Contemp. Math. 21, 179-187 (1983)

15. Du, W-S, Khojasteh, F: New results and generalizations for approximate fixed point property and their applications. Abstr. Appl. Anal. 2014, Article ID 581267 (2014). doi:10.1155/2014/581267

16. Zhang, Q, Song, Y: Fixed point theory for generalized $\varphi$-weak contractions. Appl. Math. Lett. 22, 75-78 (2009)

doi:10.1186/1687-1812-2014-195

Cite this article as: Javahernia et al.: Common fixed point of the generalized Mizoguchi-Takahashi's type contractions. Fixed Point Theory and Applications 2014 2014:195.

\section{Submit your manuscript to a SpringerOpen ${ }^{\odot}$ journal and benefit from:}

- Convenient online submission

- Rigorous peer review

- Immediate publication on acceptance

- Open access: articles freely available online

- High visibility within the field

Retaining the copyright to your article 